\title{
Quality of Life and Life Satisfaction of Displaced Persons Living in Tokyo, Japan - The Fukushima Nuclear Power Plant Accident
}

\section{Nahoko Okamoto*}

School of Nursing, Dokkyo Medical University, 880 Kitakobayashi, Mibu Shimotsuga, Tochigi, 321-0293, Japan

*Corresponding author: Nahoko Okamoto, School of Nursing, Dokkyo Medical University, 880 Kitakobayashi, Mibu Shimotsuga, Tochigi, 321-0293, Japan, Tel: +81-282-86-1111; E-mail: Nahoko.Okamoto@gmail.com

Rec date: Dec 22, 2015, Acc date: Jan 11, 2016, Pub date: Jan 18, 2016

Copyright: ( 2016 Okamoto N. This is an open-access article distributed under the terms of the Creative Commons Attribution License, which permits unrestricted use, distribution, and reproduction in any medium, provided the original author and source are credited.

\begin{abstract}
The nuclear power plant accident in Fukushima has a long- term impact on the health of the affected population than natural disasters. The aims of this study was to add to this evidence base by investigating the quality of life and life satisfaction of older refugees displaced by the nuclear power plant accident in Fukushima. We carried out with twelve older people who have been moved in Tokyo. Respondents seek opportunities to talk with their friends and felt that their interactions with others were reduced. The reason why they lost their community and relationship neighbors from when they have evacuated. A majority of respondents reported that their life activities have changed after taking refuge in Tokyo.
\end{abstract}

Keywords: Fukushima; Displaced older persons; Quality of life; Life satisfaction

\section{Introduction}

The great earthquake that struck the Sanriku coast of northern Japan on 11 March 2011 caused one of the most destructive tsunamis ever. The tsunami destroyed many coast communities in its oath killing thousands of people and damaging physical infrastructure worth billions of dollars [1].

The nuclear power plant accident in Fukushima, exposed human life and environment of the highest levels of radioactive elements ever produced by previous accidents (International Atomic Energy Agency, 2011). The authorities decided to evacuate people living in a $30-\mathrm{km}$ radius around the power plant, and $20-\mathrm{km}$ zone was declared a no-go area. Overall, an estimated 260,000 of evacuees sought refuge spread across the country in the hope of security [2].

Approximately 7,500 people moved to Tokyo as mean their family persons were living in [3].

A study in Chernobyl disaster sequelae showed that perceived risks of nuclear power stood as long-term indicators of current psychological distress [4]. Several reports have documented Fukushima victims effected health problems directly attributable to radiation exposure.

Poor mental health has been argued to be particularly prevalent among evacuees who are exposed to radiation, and subsequent forced displacement often unknown to socio-community and social care needs [5-7], factors that further perpetuate risk of psychological distress $[8,9]$. Social participation is shown to have a strong impact on mortality, and this effect remains statistically significant when other factors are considered.

Social participation, social support, and feelings of loneliness are found to have indirect effects on the mortality of the Japanese elderly people through their linkages with chronic disease, functional status, and self-rated health [10].

For example, a recent study of psychological distress among refugees relocated to temporary housing following the Great East Japan Earthquake and Tsunami identified social support a range 2.50 and 1.93 times more to have serious psychological stress, and resettlement appears to preserve the pre-disaster social network of community members [8].

The aims of this study was to add to this evidence base by investigating the quality of life and life satisfaction of older refugees displaced by the nuclear power plant accident in Fukushima. To our knowledge, no previous study has investigated these outcomes within this particular population.

\section{Methods}

\section{Design}

This study employed a mixed-methods approach toward collecting and analyzing quantitative and qualitative data.

\section{Instruments}

Self-reported questionnaire was prepared. If individuals agreed to participate they self-completed the questionnaire. However, if approached participants were unable to read or write, the family member was available to verbally write in-put. The questionnaire's first section included socio-demographic and background questions including age, gender, family member, labour status, when they were displaced. The second section comprised of the reliability and validity of a multidimensional 13-item scale [11] designed to measure judgments of one's activities of daily living using a 2 point likert scale. This measure has been widely validated it has previously adopted in Japanese older people. The third section comprised the feeling that life be worth living and social relationship scale [12] which is 
Page 2 of 3

psychological screening instrument that has previously been validated for the Japanese older population.

The final section of the questionnaire asked the participants to provide any comments about their experience as an internally displaced older person. This open-ended question enabled us to collect some additional qualitative narrative data about their experiences, quality of life, life satisfaction and social condition. Prior to collecting any data, participants were provided with information letter and explain informed consent by post letter.

\section{Setting}

The study was carried out in April 2014 and took place in Nerima city in Tokyo, which has an estimated 300 evacuees from affected area [13]. Nerima city is one of the twenty three special wards in Tokyo and is located in the northwest part of the Tokyo Metropolitan.

In 2011, the Metropolitan Government decided to receive internally displaced people particularly from Fukushima. Over 3,555 internally displaced evacuees were to settle among 3,0002 temporary houses [13] erected across 32 cities of Tokyo Metropolitan.

Most cities provided them large public apartments with gathering as temporary houses, however the accommodation of Nerima city provided them small resident apartment without gathering as placed. Due to no gathering displacement persons, have limited access to hometown community, friends, and neighbors of Fukushima town.

These less communication with social community have exposed internally displaced older people to social problems and mental stress [14], and report have also highlighted the psychosocial well-being of individuals and community for core element of resilience due to a lack of inadequate knowledge and education.

\section{Sampling}

Nerima city office exerted large efforts for group allocation for displacement persons aged 65 years older. The study subjects were local residents who living in temporary housing or family houses.

Out of the original sample, 19 subjects met first respondents and 12 subjects were eligible to participate in the study.

\section{Data analysis}

Study quantitative data were analyzed IBM SPSS (version 21; IBM Corp., Armon, NY, USA). Data clearing and checking were first conducted.

A descriptive analysis examining the sample characteristics and central tendencies of two study outcome measures (TMIG, K-l scale) was conducted. As the data sample size was too small thus statistics using non-parametric test carried out.

Narrative data collected from the open-ended survey question were analyzed using thematic analysis that involved categorizing the content of the data into themes that emerged from the data collected.

\section{Ethics Approval}

Ethical approval for the study was received on March 2014 from the Japanese Red Cross College of Nursing's for Ethical Committee. All participants were provided informed consent.

\section{Results}

Twelve internally displaced older persons were successfully recruited, 7 of whom were female and 5 male. Internally displaced older persons characteristic can be viewed in Table 1.

\begin{tabular}{|l|l|}
\hline & N=12 \\
\hline Gender & \\
\hline Male & 5 \\
\hline Female & 7 \\
\hline Age (Years) & \\
\hline $60-69$ & 1 \\
\hline $70-79$ & 6 \\
\hline $80-89$ & 4 \\
\hline Family group & 1 \\
\hline Alone & 2 \\
\hline Couple & 6 \\
\hline With child & 4 \\
\hline Others & 1 \\
\hline
\end{tabular}

Table 1: Participant background.

Nine participants stated that they receive support for their health or welfare from governmental organizations, two participants reported support from family members.

Mean TMIG and K-1 scores were 11.7(SD=2.3) and 25.5(SD=1.5) before displaced, $10(\mathrm{SD}=1.8)$ and $13.67(\mathrm{SD}=3.6)$ after displaced respectively. A breakdown of the central tendency values of two study outcome measures can be seen in Table 2 .

\begin{tabular}{|l|l|l|l|l|}
\hline & \multicolumn{2}{|l|}{$\begin{array}{l}\text { TMIG } \\
\text { score=0, highest=13) }\end{array}$} & \multicolumn{2}{|c|}{$\begin{array}{l}\text { K-I (lowest possible } \\
\text { score=0, highest=32 }\end{array}$} \\
\hline & $\begin{array}{l}\text { Before } \\
\text { displayed }\end{array}$ & $\begin{array}{l}\text { After } \\
\text { displayed }\end{array}$ & $\begin{array}{l}\text { Before } \\
\text { displayed }\end{array}$ & $\begin{array}{l}\text { After } \\
\text { displayed }\end{array}$ \\
\hline Mean & 11.7 & 10 & 25.5 & 13.67 \\
\hline SD & 2.3 & 1.8 & 1.5 & 3.6 \\
\hline Median & 12 & 10 & 26 & 14 \\
\hline Range & $7-13$ & $5-12$ & $17-32$ & $5-19$ \\
\hline
\end{tabular}

Table 2: Central tendencies of study outcome measures.

No significant relationships between background variables and outcome variables were identified.

Eight participants provided additional qualitative comments about their experience as an internally displaced older person from which the following three themes emerged. The theme 'unhappy with internally displaced person's represents participants' on going dissatisfaction and sadness with life as internally displaced person living in temporary housing, and the anxiety that life will continue or not for as long as they remain in Tokyo. Example quotes that reflect this are "I am 
worried about my future and my life in here," "I am fear in my life because I cannot go back my hometown."

Another theme was "unhappy without social-communication" which highlights internally displaced older person's dissatisfaction with the lack of communication they had relationship with neighbors and friends and the access that community events organized in unknown location and not the wellbeing of internally displaced older person. Quotes from this theme include: "It is difficult to join the event of entertainment the government provided because the place is unknown.", "I do not have friend around me, and not receive information my community members where live in."

Internally displaced older person expressed 'living in fear' which including the anxiety of being attacked and also the desire to return home but the fear in doing so. Example quotes of this theme included: "I want to go back my ground but I am scared."

\section{Conclusions}

These study present poor activities of daily living and wellbeing, including anxiety and fear. The key implication of this study's findings is that the type of stricken Nuclear Power Plant Accident forced internal displacement observed in this study is harmful for overall daily living and wellbeing. Individuals in these circumstances require socio-communication with their community members. This presents a formidable challenge for social, complex health and social care needs exits. The challenge in compounded by problems of isolation, resource capacity and lack of awareness in service function and availability.

\section{Acknowledgements}

The study was supported in part by the Japanese Red Cross College of Nursing Research Fund. The author thanks participants and Nerima city office.

\section{References}

1. Japan Science and Technology Agency (2011) The Great East Japan Earthquake Information.
2. (2014) Fire and Disaster Management Victim Report 2013.

3. (2014) Reconstruction Agency Refugees Report 2013.

4. Rose Marie P, Marjorie F (2007) Chernobyl Disaster Sequelae in Recent Immigrants to the United States from the former Soviet Union (FSU). J Immigrant Health 9: 115-124.

5. Getanda EM, Papadopoulos C, Evans H (2015) The mental health, quality of life and life satisfaction of internally displaced persons living in Nakuru County, Kenya. BMC Public Health 15: 755.

6. Hori A, Tsumuraya K, Kanamori R, Maeda M, Yabe H, et al. (2014) Report from Minamisoma city and complexity of psychological distress in local residents after a nuclear power plant accident. Seishin Shinkeigaku Zasshi, 116: 212-218.

7. Cwikel J, Rozovski U (1998) Coping with the stress of immigration among new immigrants to Israel from Commonwealth of Independent States (CIS) who were exposed to Chernobyl: the effect of age. Int J Aging Hum Dev 46: 305-318.

8. Shihoko K, Jun A, Ichiro K, Naoki K, S V Subramanian, et al. (2014) Social Support Improves Mental Health among the Victims Relocated to Temporary Housing following the Great East Japan Earthquake and Tsunami. Tohoku J.Exp.Med, 234: 241-247.

9. Nomura S, Blangiardo M, Tsubokura M, Nishikawa Y, Gilmour S, et al (2016) Post-nuclear disaster evacuation and survival amongst elderly people in Fukushima: A comparative analysis between evacuees and nonevacuees. Prev Med 82: 77-82.

10. Sugisawa H, Liang J, Liu X (1994) Social networks, social support, and mortality among older people in Japan. Journal of Gerontology, 49: 3-13.

11. Koyano W, Shibata H, Nakazato K, Haga H, Suyama Y (1991) Measurement of competence: reliability and validity of the TMIG Index of Competence. Arch Gerontol Geriatr 13: 103-116.

12. Kondo T, Kamada J (2003) Construction of 'the K-1 scale for the Feeling that life is Worth Living among the Aged' and Definition of this Feeling. J Social Welfare 43: 93-101.

13. Tokyo Metropolitan Government (2013) Disaster Prevention Information.

14. Shunichi Y, Noboru T (2015) Post-crisis efforts towards recovery and resilience after the Fukushima Daiichi Nuclear Power Plant Accident. J Clinical Oncology, 45: 700-707. 